\title{
Implementation of a Flaw Model to the Fracturing Around a Vertical Shaft
}

\author{
By \\ B. Van de Steen ${ }^{1}$, A. Vervoort $^{1}$, J. A. L. Napier ${ }^{2}$, and R. J. Durrheim ${ }^{2}$ \\ ${ }^{1}$ Department of Civil Engineering, Katholieke Universiteit Leuven, Belgium \\ ${ }^{2}$ CSIR Miningtek, Johannesburg, South Africa
}

Received June 5, 2001; accepted September 24, 2002;

Published online January 21, 2003 C Springer-Verlag 2003

\begin{abstract}
Summary
This paper investigates whether a micromechanical model developed to investigate the relation between the basic failure processes at grain-scale and the macroscopic failure pattern can be applied to model the fracturing around large-scale excavations. The simulated fracture pattern around a vertical shaft is compared to the fracturing around a shaft at a depth of $3400 \mathrm{~m}$. The simulations suggest that wedge-shaped zones, called dog-ears, are formed by a progressive splitting-like failure of the rock. The fractures forming these slabs nucleate in the zones subjected to the highest compressive stresses. Both shear and tensile mechanisms are responsible for the fracturing. The dog-ears deepen and widen as spalling continues.
\end{abstract}

Keywords: Fracture mechanics, instability, numerical simulation, shaft excavation, boundary elements.

\section{Introduction}

A fundamental understanding is required of the fracture initiation and growth processes in rock to understand the fracturing around large-scale excavations in highly stressed rock masses. A flaw model based on the displacement discontinuity method was used to simulate the fracture pattern in a series of laboratory tests (Sellers and Napier, 1997; Van de Steen et al., 2001; Van de Steen, 2001). The size of the samples ranged from a few centimetres to a few decimetres. Various configurations have been considered, including the uniaxial compressive test, the triaxial test, the Brazilian test and a diametrically loaded disc with a hole. The latter configuration contains a hole of a few millimetres in diameter. The hole induces a strong stress gradient. At the scale of the laboratory experiments, the macroscopic fracture pattern was satisfactorily simulated with elements ranging in size from $0.35 \mathrm{~mm}$ to $2.00 \mathrm{~mm}$, depending on the configuration. In these models, it is 
assumed that the basic failure processes are controlled by the stress distribution around cracks and fractures. The granular nature of the material, as well as the presence of pre-existing defects is taken into account. Applied in the boundary element code DIGS (Discontinuity Interaction and Growth Simulation) (Napier, 1990), the flaw model satisfactorily simulates the transition of the rock from what is essentially a linear elastic continuum to a discontinuum. The fundamental processes of fracture growth, the mutual interaction of fractures and the interaction of fractures with pre-existing defects as well as the localisation process are all captured by the model and the code.

In order to reach the goal of describing macrofracture processes that occur in mining or other geotechnical applications, it is important that a model can summarise efficiently the finer level fracture behaviour. In this paper, the flaw model is applied to the fracturing around a vertical shaft, showing that the model can also be used for the simulation of the fracturing around large-scale excavations.

\section{Flaw Model}

Micromechanical observations (Hallbauer et al., 1973; Olsson and Peng, 1976; Kranz, 1983) indicate that fracture initiation and fracture growth in brittle rock are to a large extent influenced by the presence of different types of defects that introduce a heterogeneity in the stress distribution. These defects include matrix and grain inhomogeneities, pre-existing cracks, strings of grain boundary cavities, interfaces between mineral grains with different elastic properties and similar heterogeneities and discontinuities. As the number, the properties and the distribution of all these defects are not known, they cannot be modelled individually. Therefore, equivalent structures are introduced, termed flaws. These flaws, incorporating the effect of the defects, are randomly distributed over the sample. At the end of this section, it is explained how the flaws are incorporated in the numerical code.

The two-dimensional boundary element code DIGS (in this study, with plane strain conditions) allows for an explicit fracture modelling (Napier, 1990; Napier and Hildyard, 1992; Napier and Peirce, 1995; Malan and Napier, 1995; Kuijpers and Napier, 1996; Napier et al., 1997; Napier and Malan, 1997). In this study, the plane strain conditions are applied. If the initial failure process can be represented by small strain dislocations, and if dynamic effects can be discarded, the cracks can be modelled as displacement discontinuities. The displacement discontinuity boundary element method (Crouch and Starfield, 1983) forms the basis of the code. In an elastic solid, the displacements are assumed to be continuous, except over the discontinuity elements. All non-linear effects in the model are contained in and reflected by the displacement discontinuities. The material between the displacement discontinuities remains at all times linear elastic. Over straight-line elements with normal vector components $n_{y}$ and $n_{z}$, centred on the $y$-axis of a local coordinate system $y-z$ (Fig. 1) and length $2 b$, the local displacement discontinuity components are defined as:

$$
D_{i}\left(y_{Q}\right)=u_{i}\left(y_{Q}, 0_{-}\right)-u_{i}\left(y_{Q}, 0_{+}\right), \quad i=y, z ;-b \leq y_{Q} \leq b,
$$




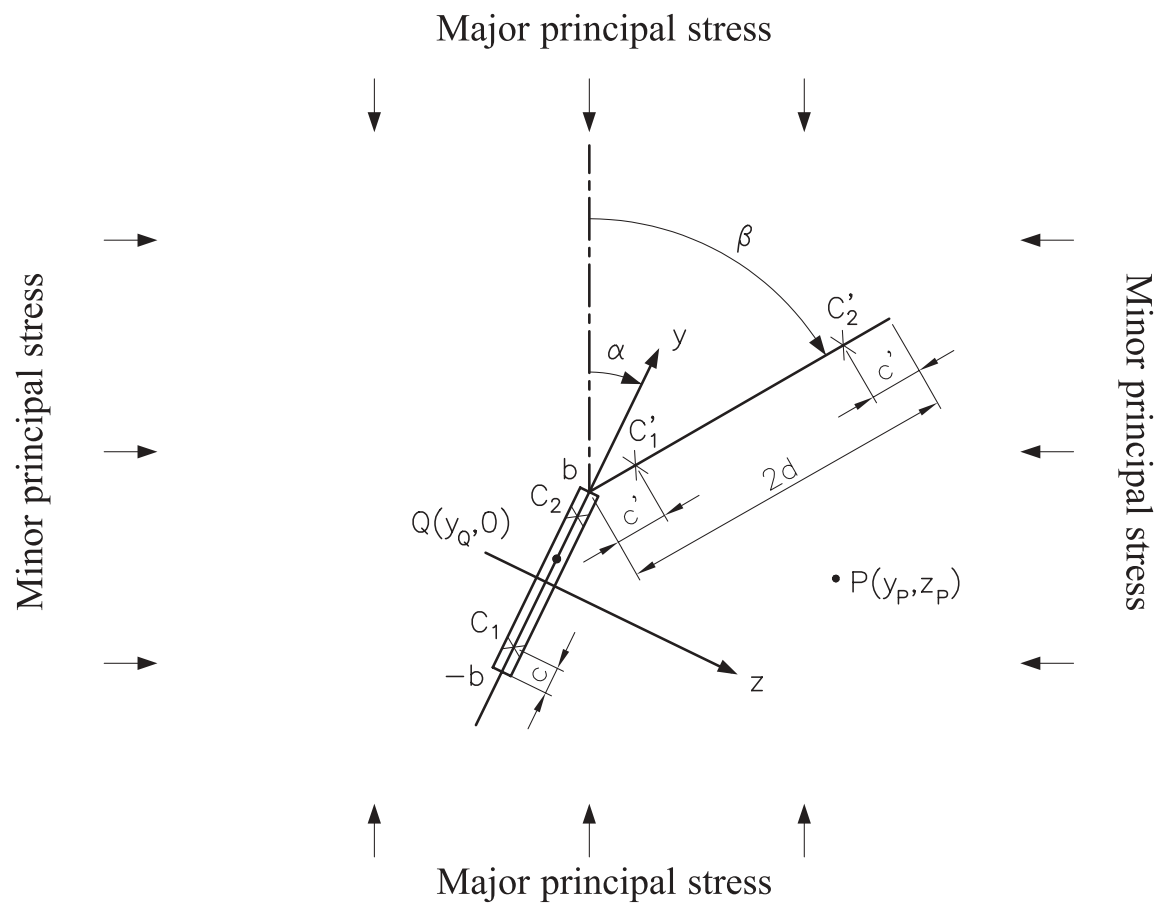

Fig. 1. Crack-element configuration with local co-ordinate system. Angles are determined with respect to the far field major principal stress direction

where $z=0_{+}$the positive side and $z=0_{-}$the negative side of the discontinuity. The displacements $u_{i}$ and the stresses over an element are represented in a number of collocation points. At these collocation points, the displacements and stresses are determined such that the boundary conditions are satisfied (Crawford and Curran, 1982). If the displacement discontinuity varies linearly over a discontinuity element with length $2 \mathrm{~b}$, as is the case in DIGS, Eq. (1) becomes:

$$
D_{i}\left(y_{Q}\right)=a_{i}+a_{i}^{\prime} y_{Q}, \quad a_{i}, a_{i}^{\prime} \text { constants }
$$

The contribution of a discontinuity element to the total stress components at a point $P\left(y_{P}, z_{P}\right)$ in isotropic elastic material with Young's modulus $E$ and Poisson's ratio $v$ is given by:

$$
\begin{aligned}
{\left[\begin{array}{c}
\sigma_{y y}\left(y_{P}, z_{P}\right) \\
\sigma_{y z}\left(y_{P}, z_{P}\right) \\
\sigma_{z z}\left(y_{P}, z_{P}\right)
\end{array}\right]=} & \frac{E}{8 \pi\left(1-v^{2}\right)} \int_{-b}^{b}\left[\begin{array}{ccc}
-\Gamma_{, z z z z} & \Gamma_{, y z z z} & -\Gamma_{, y y z z} \\
\Gamma_{, y z z z} & -\Gamma_{, y y z z} & \Gamma_{, z z z z} \\
-\Gamma_{, y y z z} & \Gamma_{, y y y z} & -\Gamma_{, y y y y}
\end{array}\right] \\
& \times\left[\begin{array}{c}
D_{y}\left(y_{Q}\right) n_{y} \\
D_{y}\left(y_{Q}\right) n_{z}+D_{z}\left(y_{Q}\right) n_{y} \\
D_{z}\left(y_{Q}\right) n_{z}
\end{array}\right] d y_{Q} .
\end{aligned}
$$

The comma behind $\Gamma$ denotes derivatives (that is $\Gamma_{, y y z z}=\frac{\partial^{4} \Gamma}{\partial y^{2} \partial z^{2}}$ ). 
For two-dimensional plane strain problems:

$$
\Gamma=\frac{1}{2}\left(r^{2}-r^{2} \log r^{2}\right)
$$

and $r^{2}=\left(y_{P}-y_{Q}\right)^{2}+z_{P}^{2}$.

The normal stress on the $y$-axis of the local co-ordinate system is given by:

$$
\sigma_{z z}(y, 0)=\frac{E}{8 \pi\left(1-v^{2}\right)}\left[2\left(\alpha_{z}+\beta_{z} y\right)\left(\frac{1}{y+b}-\frac{1}{y-b}\right)+\beta_{z} \log \left(\frac{y+b}{y-b}\right)^{2}\right] .
$$

It is obvious from Eq. (4) that the stress values for $y= \pm b$ become singular. This requires that the collocation points at which the stresses and displacements are determined have to be placed inside the elements.

The total stress values at point $P$ are given by summing the contributions defined in Eq. (3). This sum is made up of the contributions of all discontinuity elements representing the sample geometry or the excavation, and the cracks and fractures within the material.

A fracture in rock seldom forms a straight, smooth line but generally follows an irregular broken path (Zhao et al., 1993; Liu et al., 2000). This indicates that the structure of the rock has a profound effect on the actual fracture path. Although these features may be oriented less than optimally with respect to the orientation of the stresses, they are often activated. A grid defining these features can be devised to represent these structural characteristics. In the model, the fracturing is restricted to the elements defined by a random grid. The random grid is generated by a Delaunay-Voronoi generator. After generating a random set of points (= sites) in the area to be meshed, triangles (Delaunay) or polygons (Voronoi) are constructed (Finney, 1979; Malan and Napier, 1995; Napier and Peirce, 1995). The geometric centre of each polygon is connected to its vertices, effectively subdividing each polygon in a number of triangles (modified Voronoi tessellation) to obtain a sufficient number of fracture growth directions (Van de Steen et al., 2001).

Each of the edges of the above-mentioned triangles is assigned a failure criterion and a set of matching strength properties. A randomly selected subset of these edges, is designated as flaws. They are given reduced strength properties. For a certain load value (e.g. in the case of the shaft simulations, the far field stresses), the stresses at all the collocation point positions are evaluated against the failure criterion of each yet non-mobilised element. One or more of the elements for which the failure criterion is exceeded at one of the collocation points can be activated in a particular calculation step according to a pre-defined priority rule to become a displacement discontinuity in the true sense. Under the applied load and with the new displacement discontinuities in place, the interacting displacement discontinuities undergo both sliding and opening movements, which are calculated through an iterative scheme. Since they have reduced strength properties, it is evident that the flaws are the first element(s) to be activated in the zones with the most critical stress conditions. In the next calculation step, the stress redistribution is calculated taking into account the mobilised displacement discontinuities. Again 
the most favourable element(s) are activated and the process is repeated. In this way, the fracture pattern grows in successive calculation steps, without a change in the external load. Even that no time laws are specified the simulated results give an impression of how a fracture pattern could grow over time. It is also possible to increase the external load in successive steps. This procedure is very interesting for simulating the loading sequence in laboratory experiments (e.g. Van de Steen et al., 2001).

\section{Observations}

Before describing the fracturing around a vertical shaft at Western Deep Levels South (North West Province, South Africa) at a depth of $3400 \mathrm{~m}$, the shaft sinking method and the pre-mining in situ stresses are discussed.

The shaft was sunk in quartzite, widening a 3-m diameter pre-bored hole to a diameter of $10 \mathrm{~m}$. For large diameter shafts, the technique of widening a raisebored shaft is a common and cheap alternative to conventional sinking. However, the ground conditions must allow the unsupported raise-bored shaft to stand up, and the bottom of the prospective shaft must be accessible.

A pilot hole with a diameter of typically $279 \mathrm{~mm}$ to $349 \mathrm{~mm}\left(11^{\prime \prime}\right.$ to $\left.13 \frac{3}{4}{ }^{\prime \prime}\right)$ is drilled from the top to the bottom of the prospective shaft. The drill rod is fitted with stabilisers to minimise the deviation. Cuttings are flushed out with water or compressed air. At the bottom, a reamer is then mounted to the drill rod. The reamer has a diameter that typically varies between $0.66 \mathrm{~m}$ and $6.0 \mathrm{~m}$. While the machine pulls the drill rod back, the rock is ground into fragments by the cutters on the rotating reamer. The debris falls down by gravity. At the bottom, it can be removed easily by a Load Haul Dump (LHD) machine. Once the raise has been bored over the full height, the machine is disassembled, and the final diameter is achieved by drill and blast operations. As with conventional shaft sinking, the drill and blast operations advance from the top to the bottom of the shaft. The bored raise provides a free face for the blasting operations, considerably improving the efficiency of the process. The debris falls down the raise and a LHD removes it at the bottom.

At the site being considered, the major principal stress coincides with the vertical stress. The vertical stress gradient is estimated at $2.7 \mathrm{MPa}$ per $100 \mathrm{~m}$. Hence, at a depth of $3400 \mathrm{~m}$ the pre-mining major principal stress $\sigma_{v}=92 \mathrm{MPa}$. With a ratio of $\sigma_{h}$ to $\sigma_{H}$ equal to 0.7 , the horizontal stress field is anisotropic. The ratio of $\sigma_{H}$ to $\sigma_{v}$ is also of the order of 0.7 ; hence, $\sigma_{h}=46 \mathrm{MPa}$ and $\sigma_{H}=65 \mathrm{MPa}$.

The observations of the fracturing around the 3-m pre-bored raise are based on the fracturing viewed from the face of the shaft widening operations. The fracturing around the 10-m diameter vertical shaft (Kuijpers, 1999) was exposed when a station was cut at a depth of $3400 \mathrm{~m}$.

The fracturing around the 3-m diameter raise is estimated based on observations of scaling and fracturing of the wall of the hole as seen looking down the raise. As it fell down the bored raise, the debris of the shaft-widening operation removed the heavily fractured rock from a wedge shaped area, commonly known as a 'dog-ear'. This dog-ear extends in the $\sigma_{h}$-direction (Fig. 2). The distance from 


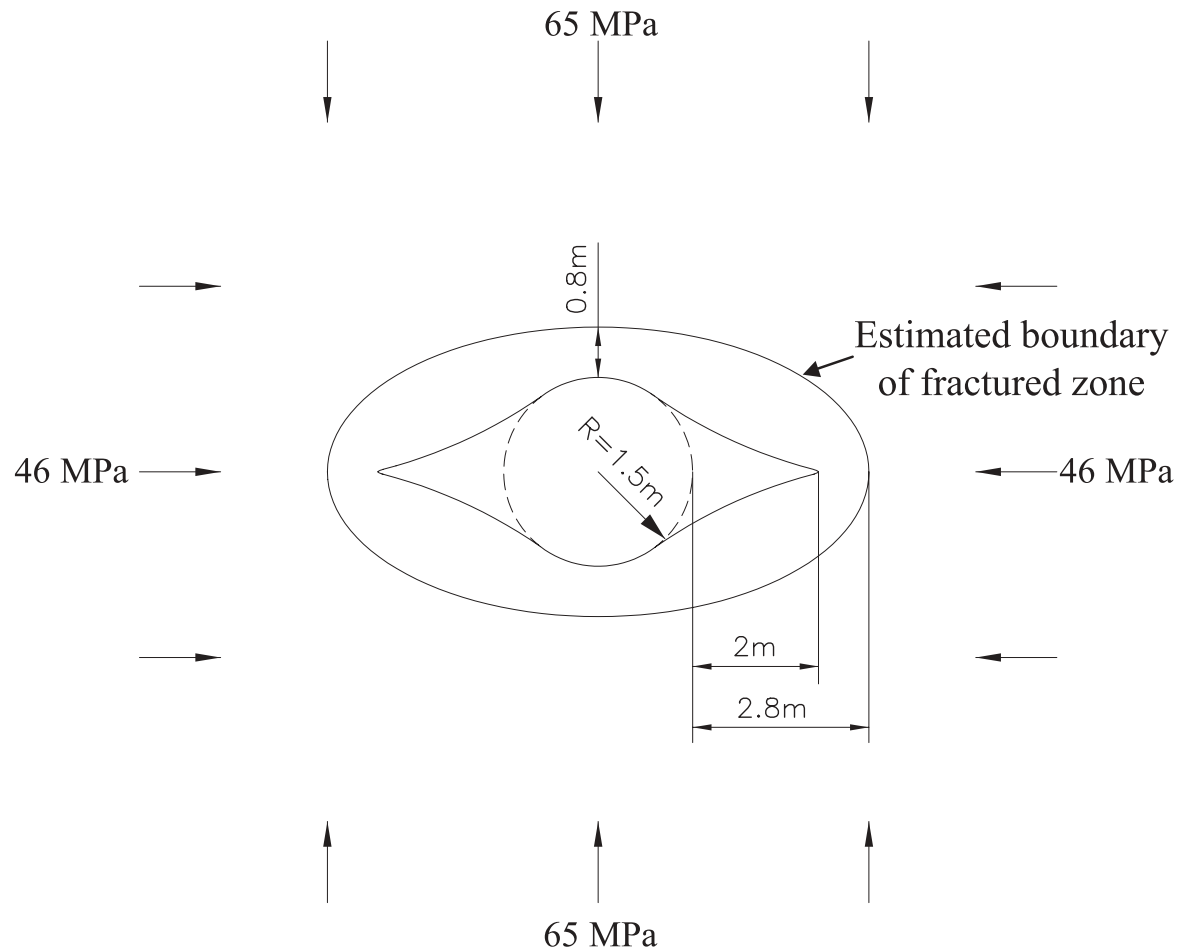

Fig. 2. Sketch of the fracture pattern observed around the 3-m diameter raise

the tip of the dog-ear to the original bored wall was approximately $2 \mathrm{~m}$. On the $\sigma_{H}$-side, the original bored wall was still in place. There is evidence that fracturing extends to $0.8 \mathrm{~m}$ beyond the scaled hole-perimeter. These fractures seem parallel to the wall of the hole. The shape of the fractured area is thought to be almost elliptic. The ellipticity of this area is defined as the ratio of the major axis to the minor axis of the circumscribed ellipse and amounts to approximately 1.9.

Around the 10-m diameter shaft, the fracturing observed at the station reflects the anisotropy in the horizontal stresses. In the $\sigma_{H}$-direction, the fractures curve around the shaft to extend tangentially away from the shaft perimeter in the $\sigma_{h^{-}}$ direction to form a wedge (Figs. 3 and 4). In the dog-ear, the fractures of the two opposite sides converge. The tip of the wedge is situated at a depth of approximately $1.8 \mathrm{~m}$ from the shaft perimeter. The area defined by the dog-ears is intensely fractured. In contrast to the $3-\mathrm{m}$ diameter raise, the material is still in place in the dog-ear. There are more fractures beyond the dog-ear, defining a more or less elliptic zone of fractured rock around the shaft. The total depth of fracturing on the $\sigma_{h}$-side extends to a distance of $2.2 \mathrm{~m}$ from the shaft perimeter. On the $\sigma_{H}$-side, the fracturing extends to a depth of $1.3 \mathrm{~m}$ only. Estimated at 1.1 , the ellipticity of the fracturing around the $10-\mathrm{m}$ diameter shaft is not as pronounced as around the 3-m diameter raise.

Around circular openings, the formation of dog-ears is an often-observed fail- 


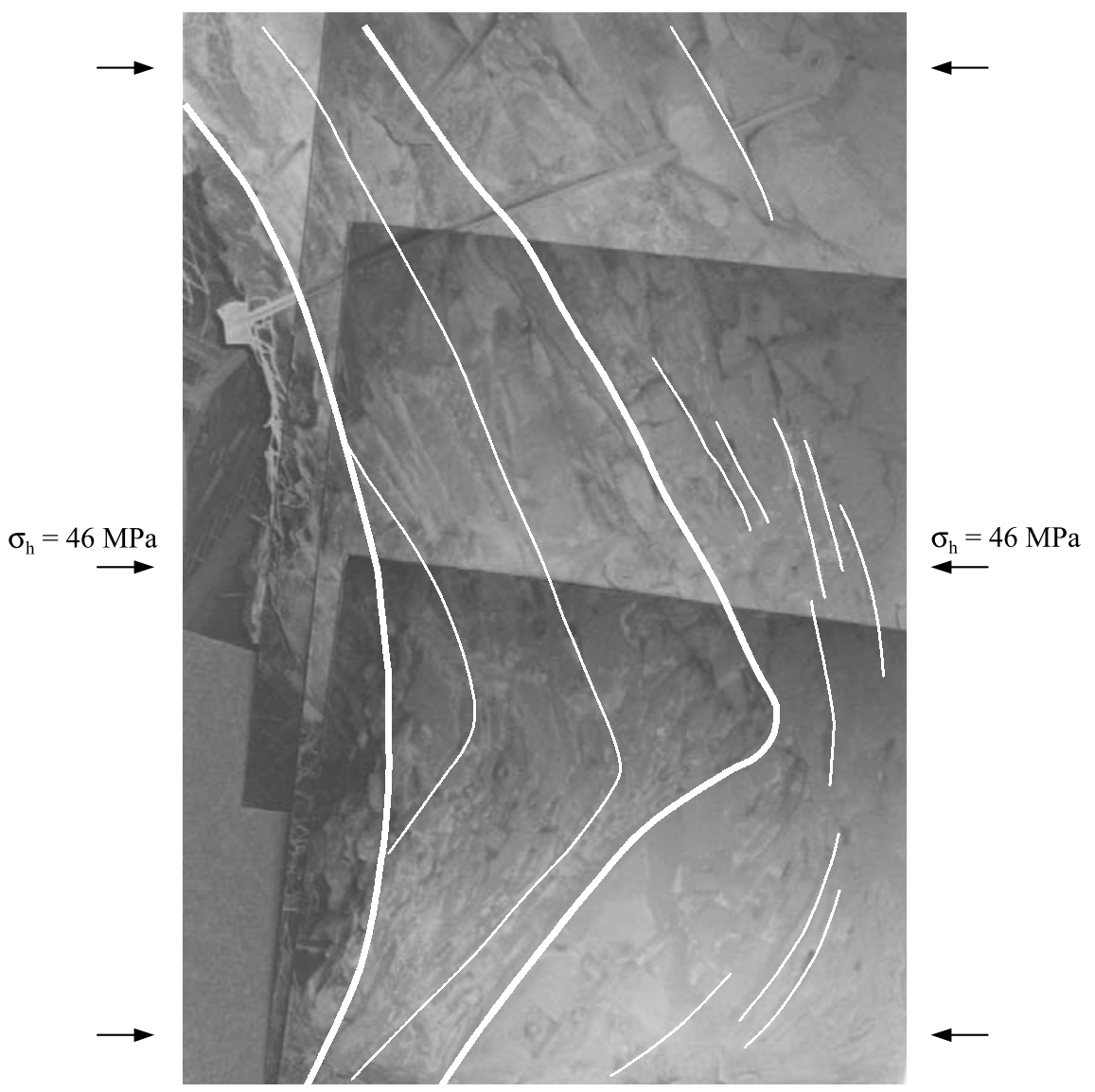

Fig. 3. Photograph of the fracturing around $10-\mathrm{m}$ diameter vertical shaft at a depth of $3400 \mathrm{~m}$. The shaft wall, the delineation of the dog-ear, a few of the fractures inside the dog-ear and a few of the fractures outside the dog-ear are indicated

ure pattern. The fundamental mechanism causing the dog-earing remains under discussion. The dog-earing is attributed to either the tension-driven growth of fractures parallel or sub-parallel to the major principal stress direction or to the formation and growth of shear fractures.

\section{DIGS Simulations}

The small-scale heterogeneities and defects (e.g. micro-fractures, grain contacts and pores) present in the relatively small rock samples tested in the laboratory, are also present in the rock mass surrounding an excavation. They undeniably play a role in the fracture nucleation and growth process in the rock mass. The applicability of a scaled-up flaw model to large-scale problems is in the first place determined by the quality of the simulated fracture pattern. In the context of the scaledup model the flaws can be considered as larger discontinuities or as the combined 


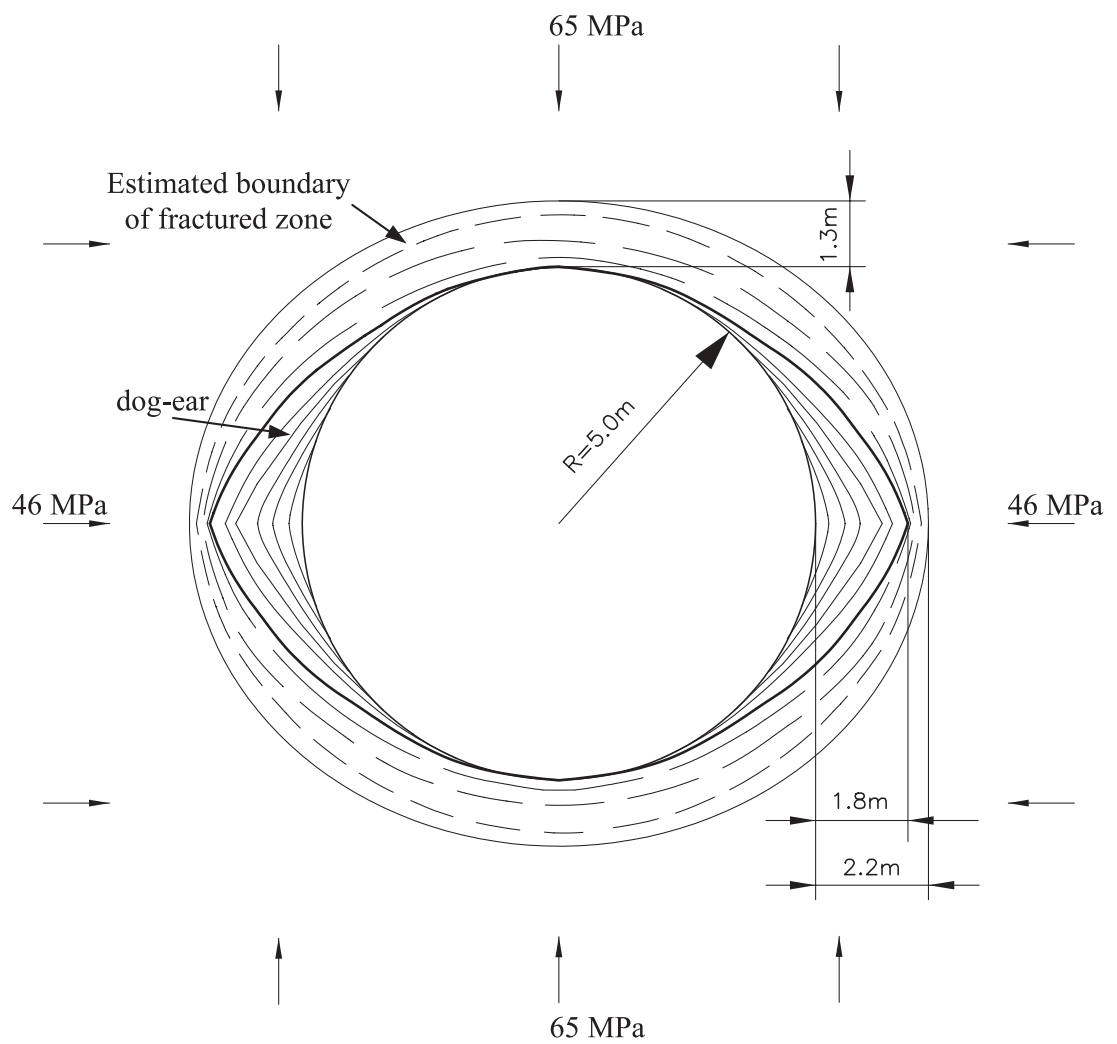

Fig. 4. Sketch of the fracture pattern observed around 10-m diameter shaft

effect of smaller defects forming larger weakness zones. The large discontinuities consist of structural features such as bedding planes, joints and even faults, of newly induced fractures in the solid rock mass due to the stress redistribution and of fractures induced during blasting operations.

A two-dimensional model is used with the plane strain conditions. In the case studied here, it is implicitly assumed that the pore pressures are equal to zero and that the rock is not supported as the fracturing develops. It is in other words assumed that wire mesh, rock anchors or any other form of support is installed after the fracturing has fully developed. At the time of fracturing, the radial stresses are therefore zero at the hole perimeter. With $\sigma_{v}=92 \mathrm{MPa}, \sigma_{H}=65 \mathrm{MPa}$, $\sigma_{h}=46 \mathrm{MPa}$, and $v=0.2$, the largest deviatoric stress is reached in a horizontal plane for $\theta=+/-\pi / 2$ and $r=R: \sigma_{\theta}-\sigma_{r}=\left(3 \sigma_{H}-\sigma_{h}\right)-\sigma_{r}=149 \mathrm{MPa}$. In this area of the circumference the horizontal deviatoric stress is larger than the deviatoric stress in a radial plane (e.g. for $\theta=+/-\pi / 2$ and $r=R: \sigma_{\theta}-\sigma_{v}=$ $\left(3 \sigma_{H}-\sigma_{h}\right)-\sigma_{v}=149-92 \mathrm{MPa}=57 \mathrm{MPa}$. However, for $\theta=0$ or $\pi$, and $r=R$, the tangential stress $\left(\sigma_{\theta}=3 \sigma_{h}-\sigma_{H}=73 \mathrm{MPa}\right)$ is the intermediate principal stress and the largest deviatoric stress occurs in the radial plane $\left(\sigma_{v}-\sigma_{r}=92 \mathrm{MPa}\right)$. As this value is smaller than the horizontal deviatoric stress for $\theta=+/-\pi / 2$ and 
$r=R$, and as most fractures are observed in the quarter around $\theta=+/-\pi / 2$, it is logic to position the $2 \mathrm{D}$ model in a horizontal plane. Of course, a 3D model would incorporate a full range of the various stress combinations.

By comparing the maximum deviatoric stress to the average UCS-value for quartzite at Western Deep Levels, which is $237 \mathrm{MPa}$ (Malan and Basson, 1998), the intact rock should not fail (Young's modulus $=79 \mathrm{GPa}$ ). However, Martin et al. (1999) report that brittle failure occurs if the ratio of the maximum tangential boundary stress to the laboratory unconfined compressive stress exceeds approximate to 0.4 , which is the case here (149/237 or 0.63$)$. The reduced rock strength around mining excavations can be attributed to damage induced during blasting or rock-cutting operations and to creep effects that can lead to time-dependent failure (Malan and Basson, 1998).

In large-scale problems, the size effect does not seem to further influence the stress at which damage and fracturing first appear. It is generally accepted (Ingraffea, 1987; Bažant et al., 1993; Dzik and Lajtai, 1996) that the size effect around circular holes decreases as the hole radius increases. Crack initiation stresses or borehole break-out stresses decrease as the hole radius increases, to reach a limiting value for large radii. Dzik and Lajtai (1996) define large holes as circular openings with a radius of $40 \mathrm{~mm}$ or more. The 3-m diameter raise and the $10-\mathrm{m}$ diameter shaft are clearly large diameter excavations. The fracture pattern observed around the 3-m diameter raise and the 10-m diameter shaft demonstrate that the extent of fracturing can differ considerably depending on the particular conditions prevailing before, during and after excavation (e.g. raise borer vs. explosives, with or without support, type of support and time since excavation). The fracturing around the $10-\mathrm{m}$ diameter shaft and the 3-m diameter raise are examples of fracture patterns that can occur around a shaft. The simulations are carried out on normalised shaft diameters. The size of the elements is therefore expressed relative to the size of the shaft radius. The rock surrounding the shaft is tessellated with a Voronoi tessellation with internal fracture paths. Advantage is taken of the double symmetry in the shaft configuration to limit the calculation time. In the simulations, the applied far field stresses correspond to $\sigma_{h}$ and $\sigma_{H}$. These stresses remain constant through the entire simulation, namely for all the calculation steps. In a similar way, the radial stress (i.e. support pressure) on the circular excavation is zero from the start of the simulations. The mesh characteristics are given in Table 1.

Table 1. Mesh characteristics used in the simulations depicted in Fig. 5

\begin{tabular}{lllc}
\hline Number of elements & $\begin{array}{l}\text { Ratio element size } \\
\text { to radius }\end{array}$ & Standard deviation & Flaws \% \\
\hline 11704 & 0.0178 & 0.0047 & 11.91 \\
\hline
\end{tabular}

\subsection{Fracture Pattern}

Figure 5 shows the final simulated fracture pattern around the shaft. The fractures are allowed to develop incrementally in successive calculation steps following the 


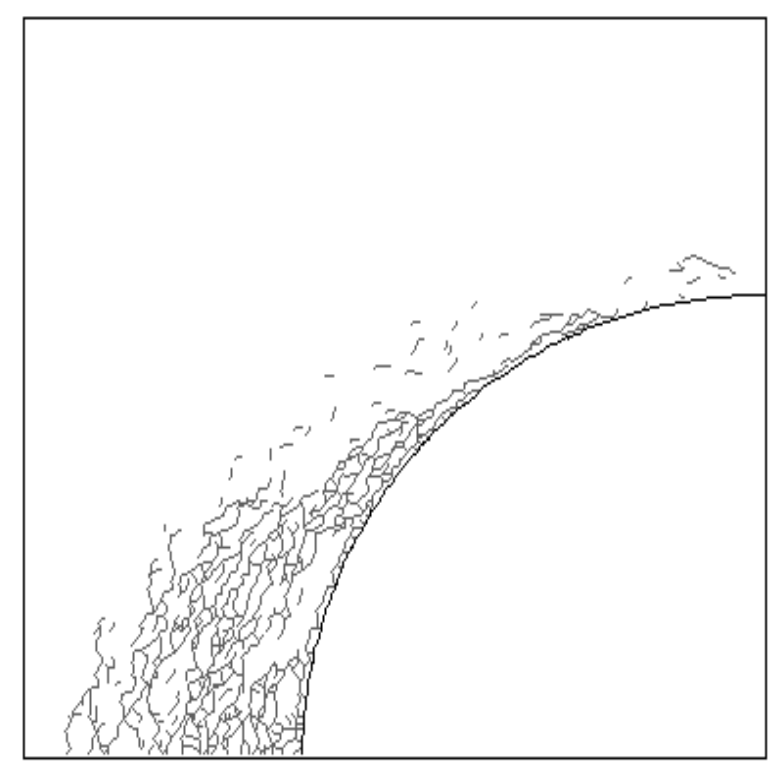

Fig. 5. Simulation of final fracture pattern around the circular shaft

solution of an initial problem containing the hole outline in the applied far field stress. The intense fracturing on the $\sigma_{h}$-side makes interpretation of the results difficult. Some graphical post-processing was applied to better emphasise the simulation results visually (Fig. 6). The fracturing sequence over successive calculation steps is given in Fig. 7 (see 4.2).

In the graphical post-processing, the full shaft geometry was reconstructed by two mirroring operations, resulting in a full picture of the fracture pattern in a horizontal plane (Fig. 6). In addition, the fracture pattern in the area containing loose blocks is replaced by a shaded zone. The loose blocks are defined as these parts of the model totally enclosed by displacement discontinuities and not tied down by boundary conditions or surrounding material. In terms of an equivalent physical model, the loose blocks would be all the fractured material that would fall out or that can be removed without further breaking the surrounding rock. The continuous line of displacement discontinuities that forms the boundary of the shaft after removal of the loose blocks, can be interpreted as the scaled perimeter (Fig. 2) or as the boundary delineating the dog-ear (Figs. 3 and 4). Finally, the ellipse circumscribing the fractured zone is also indicated on the figure.

A large part of the intensely fractured zone (Fig. 5) falls inside the shaded zone. The material in the dog-ear is more intensely fractured than the material outside this zone in both the simulation and the real situation (Fig. 3). The zone beyond the scaled perimeter has an almost constant width of $0.1 \mathrm{R}$ (Fig. 6). In this zone, the fracturing is more intense on the $\sigma_{h}$-side than on the $\sigma_{H}$-side. The observations in the real situation did not provide evidence that the intensity of fracturing is direction-dependent in the area beyond the dog-ear. 


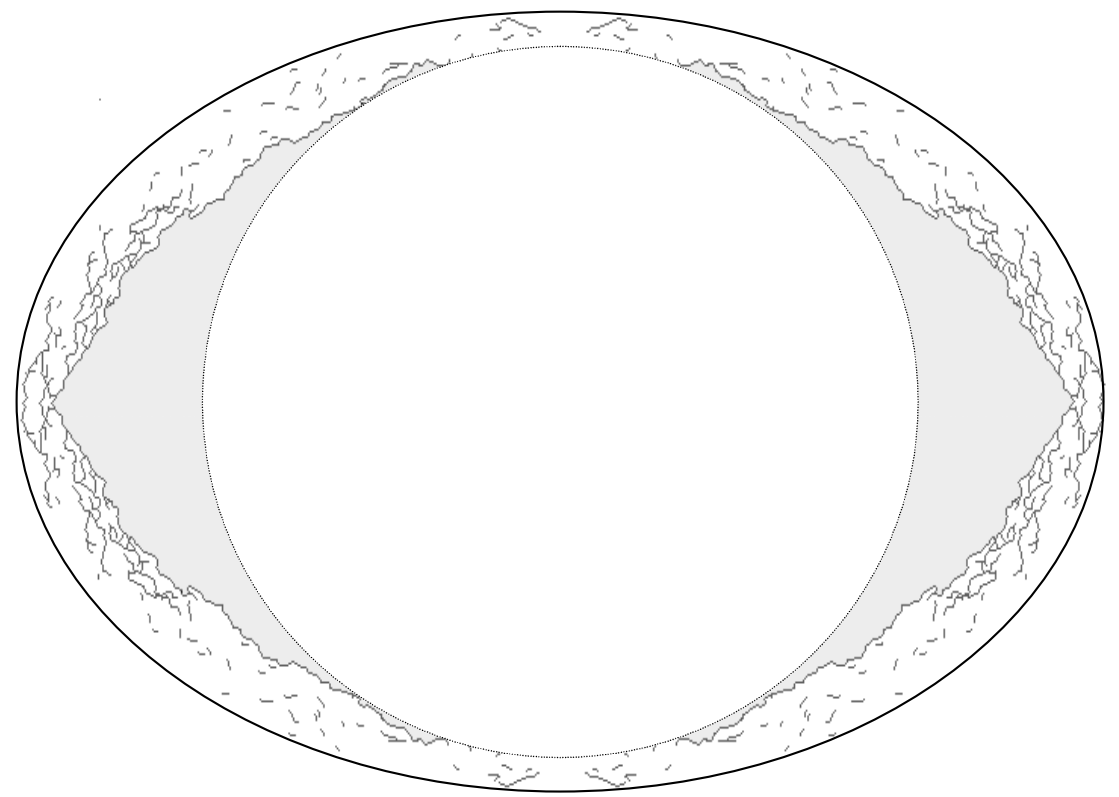

Fig. 6. Simulated final fracture pattern obtained after removing 'loose blocks'. The ellipse circumscribing the damaged zone is indicated as well

In the simulations, the fracturing depth is approximately $0.55 \mathrm{R}$ in the $\sigma_{h}$-direction and $0.1 \mathrm{R}$ in the $\sigma_{H}$-direction (Fig. 6). The ellipticity of the fractured area is equal to 1.4. As mentioned above, the ellipticity inferred from the observations is estimated at 1.1 for the $10 \mathrm{~m}$-diameter shaft and 1.9 for the $3 \mathrm{~m}$ diameter raise.

\subsection{Fracturing Sequence}

As at and around $\theta=+/-\pi / 2$ the largest deviatoric stress is situated in the horizontal plane with the tangential stress being compressive and maximum at the perimeter, while the radial is equal to zero at the perimeter, one expects that failure initiation would occur in shear at the shaft perimeter. For a linear elastic material and for an isotropic stress situation, Fjær et al. (1992) show that the growth of the shear fractures can result in pairs of shear surfaces intersecting parallel to the shaft axis. Zobak et al. (1985) considered an anisotropic horizontal stress field and they came to similar conclusions. They also suggest that the dogearing is a cyclic mechanism in which new fracture surfaces develop outside the existing ones. The stress redistribution around the fractured area would cause formation of new shear fractures at the shaft wall. Therefore, the dog-ear widens and deepens at the same time.

According to the splitting failure theory however, dog-earing is formed by the progressive spalling of the side-wall. It develops in the zones subjected to the highest compressive stresses (Carter et al., 1991; Martin, 1997; Shao et al., 1999; 
Aubertin and Simon, 2000) or in the zones with the lowest compressive strength in the tangential direction (Ewy and Cook, 1990a; Ewy and Cook, 1990b). The direction of the fractures is generally parallel or subparallel to the major principal stress direction. As shear deformations are typically absent, the fractures are generally assumed to have grown in response to excessive tensile stresses (Kuijpers, 1999). Martin et al. (1997) propose a cyclic mechanism in which shearing and crushing in the very small zone subjected to the highest compressive stress is followed by a slabbing and spalling process dominated by shearing, splitting and buckling. Although shearing does contribute to the fracture initiation and fracture growth process, the fracture is initiated at the tip of the dog-ear and not at the shaft wall. Conventional continuum models are not able to capture the spalling mechanism observed in the high compression zone.

The final fracture pattern in Fig. 5 does not immediately allow to draw conclusions about the failure mechanism (splitting failure mechanism or standard failure mechanism). The fracturing sequence is studied to establish the dominating mechanism. Thereafter the orientation of the individual displacement discontinuities and the mode in which they failed are investigated.

The DIGS simulations suggest that the circumferential extent (the width) of the dog-ear increases as the radial distance to the tip of the dog-ear increases (the depth) (Fig. 7). The fracture pattern shown in Fig. 3 indicates that this may indeed be the case. The fracturing in the final simulated fracture pattern is so intense that it is not possible to discern slabs. The different stages depicted in Fig. 7 however show that fracturing proceeds in layers. Around the shaft, the angle between the direction of the local major principal stress and the tangential direction is very small (between $0^{\circ}$ and $4^{\circ}$ ) before the start of the fracturing process. Fracturing causes a re-orientation of the principal stress directions in the immediate vicinity of the fractured area. Locally, the major principal stress becomes sub-parallel to the major fractures situated at the outside of the fractured zone. In the situation shown in Fig. 7a, a re-orientation of the stresses has already taken place. In the successive stages shown in Figs. 7b, 7c and 7e, new, almost continuous fractures (indicated by an arrow) begin to develop at the outside of the fractured zone. In Figs. $7 \mathrm{~d}$ and $7 \mathrm{f}$, the zone delineated by these fractures formed in Figs. 7c and 7e respectively, undergoes further fracturing. Most of the fractures initiate in and around the area subjected to the largest compressive stress. A few cracks are initiated at the shaft wall, but they do not develop into major fractures delineating the dog-ear as predicted by the standard failure theory.

\subsection{Failure Type and Crack Orientation}

The direction of each activated element is determined to study whether the fractures have a preferential orientation with respect to the shaft perimeter. This direction is compared to the tangential direction in the centre of the activated element (Fig. 8). The histogram of the activated element directions was split up according to the failure mechanism. Nearly half of the activated elements fail in shear. The orientation of these elements form two distinct populations (Fig. 9a) with peaks at $-35^{\circ}$ and $25^{\circ}$. The orientation of two thirds of the elements that 

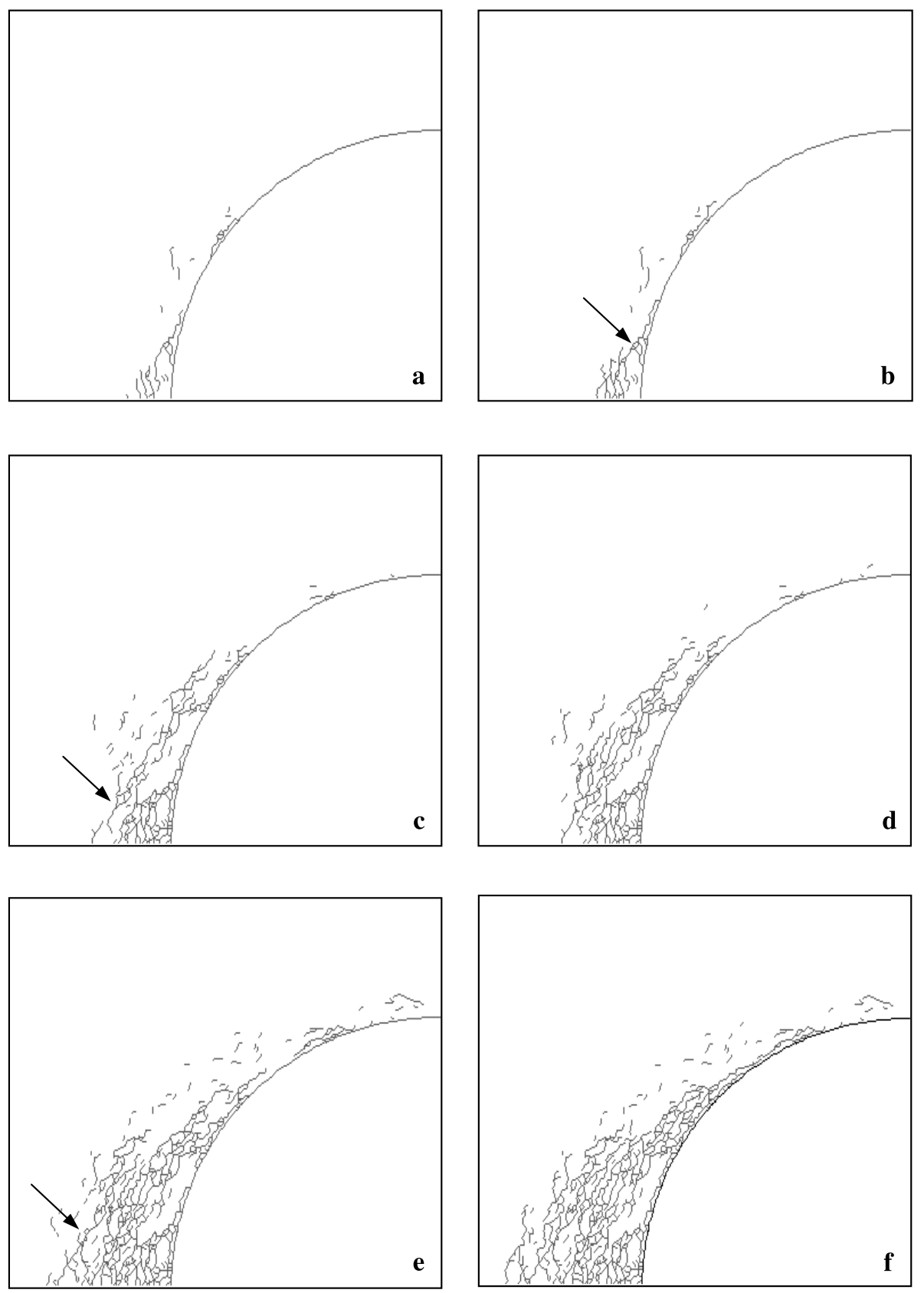

Fig. 7a-f. Fracturing sequence during successive calculation steps (same far field boundary conditions and zero support pressure). The arrows indicate the new almost continuous fractures that are formed 


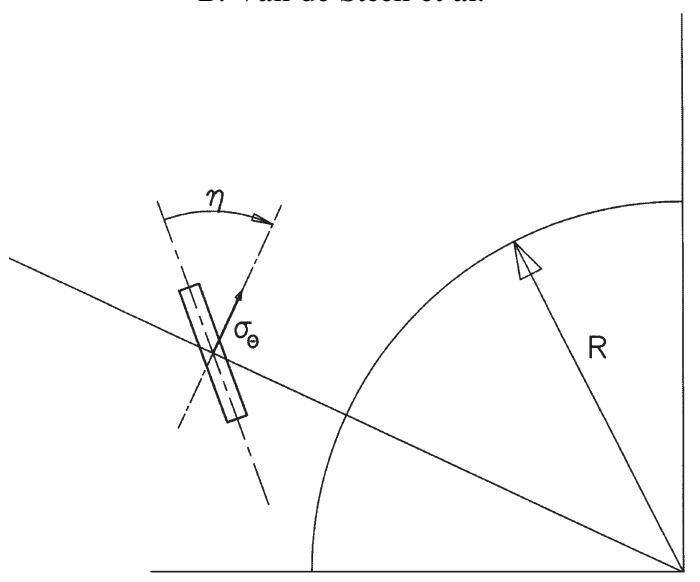

Fig. 8. Definition of direction $\eta$ between an activated element and the tangential direction

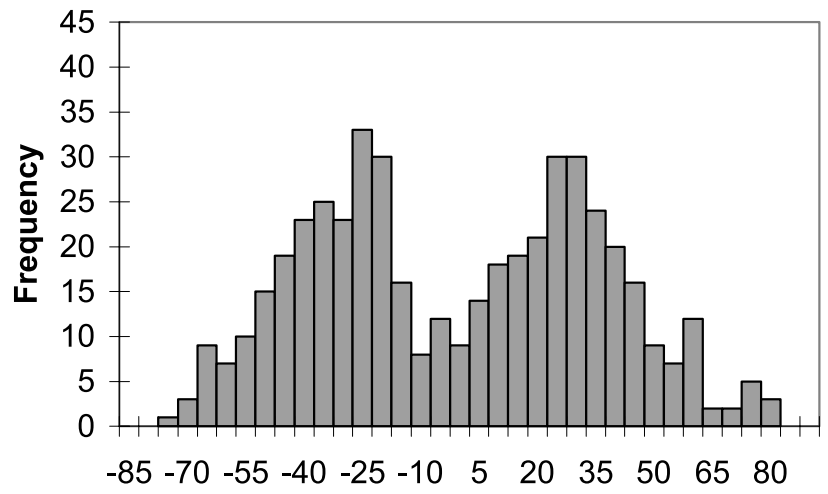

a

Angle $\eta$ of the activated elements (degrees)

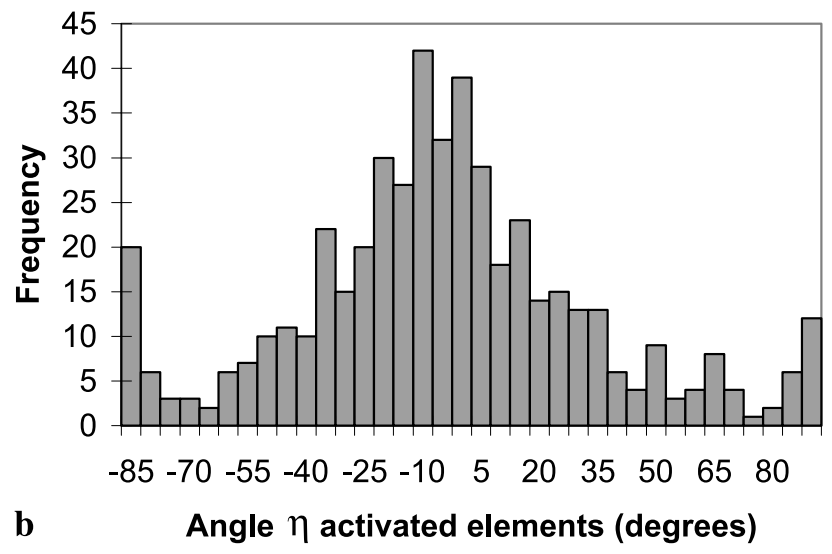

Fig. 9a,b. Orientation of activated elements, a shear, $\mathbf{b}$ tension 
fail in tension ranges between $-40^{\circ}$ and $25^{\circ}$ (Fig. 9b). A second much smaller population of the elements failing in tension are more or less radially oriented $\left(|\eta|>80^{\circ}\right)$. The radially oriented cracks are mainly found in the intensely fractured areas. They are generally some of the last fractures formed in such areas, as slender slabs of material buckle. A series of such radial fractures can be seen in Fig. 5 between the shaft perimeter and the long almost continuous fracture just beyond the perimeter. In this process, the radial fractures are breaking up thin curved slabs. Both before and after fracture growth, the orientation of the major principal stresses does not deviate much from the tangential direction in the vicinity of the shaft.

\subsection{Mesh Density}

The influence of the mesh size and the flaw density on the fracture pattern is illustrated with a series of simulations of the fracturing process around the shaft (Fig. 10). These simulations also illustrate the improvement of the quality of the simulated fracture pattern with a reduction in mesh size.

The fracture pattern shown in Fig. 10a, is the same as in Fig. 6. It has been discussed in detail in the previous sections. This simulation makes use of a relatively fine grid. Expressed into absolute sizes, the 0.0178 ratio of the element to radius size (Table 2) corresponds to $89 \mathrm{~mm}$ elements for a $10-\mathrm{m}$ diameter shaft and to $27 \mathrm{~mm}$ for a 3-m diameter shaft. The simulations resulting in the fracture pattern shown in the Figs. $10 \mathrm{~b}$ to $10 \mathrm{~d}$ make use of the same relatively coarse grid (Table 2). In terms of a $10-\mathrm{m}$ and a $3-\mathrm{m}$ diameter shaft, the 0.0548 ratio corresponds to $274 \mathrm{~mm}$ and $82 \mathrm{~mm}$ elements respectively. The main difference between the simulation shown in Fig. $10 \mathrm{~b}$ and the other simulations, is the flaw density. The parameters in the flaw generator for this model are such that the percentage of flaws is doubled. For Figs. 10c and 10d, the difference between the element mesh subjected to the simulation is solely due to the random flaw generation.

Figures. $10 \mathrm{a}$ and $10 \mathrm{~b}$ are qualitatively similar and both simulate the dog-ear and the surrounding fracturing relatively well. The main difference lies in the size of the elements. An investigation into the fracturing sequence of Fig. 10b also shows that the fracturing happens in a cyclic layer-like manner. However, in Fig. $10 \mathrm{~b}$, the resulting pattern is coarser (196 activated elements against 1075 elements), while the simulation time is 70 times smaller.

While the fracture pattern depicted in Fig. 10c still suggests that fracturing mainly occurs in the area of maximum compression, the fracturing pattern in Fig. $10 \mathrm{~d}$ does not show any resemblance with the observed fracture patterns. From Fig. 10d, it could be wrongfully inferred that fracturing around the shaft occurs in a small ring of almost constant width. The reason for the large difference in fracture pattern between Figs. 10c and 10d and for the poor result of Fig. 10d in particular, lies in the lack of suitable fracture initiation points and fracture growth possibilities.

It can be concluded that the development of the fracture pattern in the simulations depends largely on the availability of sufficient fracture growth paths and 

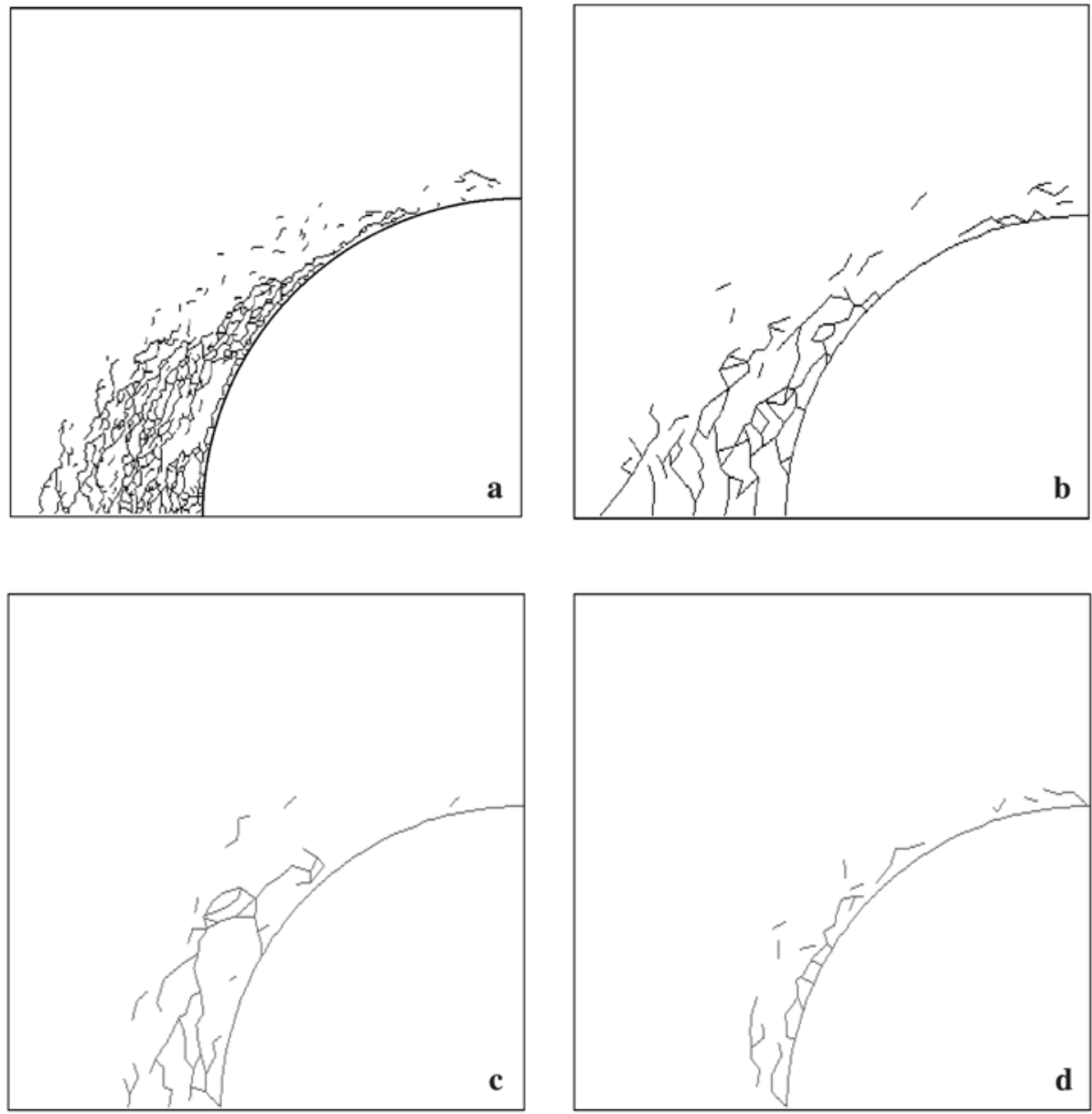

Fig. 10a-d. Influence of element size and flaw density on the simulation of the final fracture pattern around the circular shaft (see Table 2). a Reference; b Increased element size; increased flaw density; c Increased element size; case 1; d Increased element size; case 2

Table 2. Mesh characteristics used in the simulations depicted in Fig. 10

\begin{tabular}{lcccc}
\hline & Fig. 10a & Fig. 10b & Fig. 10c & Fig. 10d \\
\hline Number of elements & 11704 & 5233 & 5233 & 5233 \\
Ratio element size to radius & 0.0178 & 0.0548 & 0.0548 & 0.0548 \\
Standard deviation & 0.0047 & 0.0144 & 0.0144 & 0.0144 \\
\% flaws & 11.91 & 24.91 & 12.36 & 11.82 \\
\hline
\end{tabular}

fracture nucleation sites in the critically stressed zone. It should be clear that the question of the required mesh size is related to the size of the zone in which fracturing can initially develop rather than to the over-all size of the configuration modelled. 


\section{Discussion and Conclusions}

In this study, attention was focused on qualitative aspects of the fracturing pattern, and less attention was paid to quantitative aspects such as the slab width, the depth of the dog-ear, etc. A qualitative agreement is obtained between the fracturing in horizontal planes around a vertical shaft, and the DIGS simulations. The dog-earing and the ellipse-shaped fracturing zone around the shaft are recovered in the simulations. The magnitude and the orientation of the principal stresses around the opening change as the fractured zone develops. This re-orientation is the direct cause that the fractures seem to curve tangentially away from the shaft perimeter in the $\sigma_{h}$ direction to form a wedge, known as a dog-ear. The analysis of the failure mechanism indicates that at the scale the material is modelled, both tensile failure and shear failure play a role in the fracturing process.

On the basis of the DIGS simulations, it is concluded that the fracturing leading to dog-earing is caused by a splitting failure-type mechanism. The position of the fracture nucleation sites and the considerable role played by the tensile failure mechanism are strong indicators of this mechanism. Fractures are generated in the zone close to the tip of the dog-ear. They are not the consequence of a shear mechanism starting from the shaft wall. The simulations further show that it is a cyclic process and that a splitting failure mechanism is accompanied by an extension of both the width and the depth of the dog-ear.

In selecting the appropriate element size for the simulations, it must be ensured that the number of elements in the critically stressed zone is large enough for the fracture to develop. A balance has to be found between the number of elements and the flaw density. This should ensure that the probability of fractures nucleating and growing in the critically stressed area approaches one. The failure mechanism and the size of the zones in which fractures develop rather than the size of the configuration as a whole determines the required element size.

\section{Acknowledgements}

The simulations presented in this paper form part of the $\mathrm{PhD}$ study of B. Van de Steen at the KULeuven. The authors wish to thank the sponsors of the Deepmine project for the permission to use the information pertaining to the fracturing around the South shaft at Western Deep Levels.

\section{References}

Aubertin M., Li L., Simon R. (2000): A multiaxial stress criterion for short- and long-term strength of isotropic rock media. Int. J Rock Mech. Min. Sci. 37, 1169-1193.

Bažant Z. P., Lin F.-B., Lippmann H. (1993): Fracture energy release and size effect in borehole breakout. Int. J. Numer. Anal. Methods Geomech. 17, 1-14.

Carter B. J., Lajtai E. Z., Petukhov A. (1991): Primary and remote fractures around underground cavities. Int. J Numer. Anal. Methods Geomech. 15, 21-40.

Crawford A. M., Curran J. H. (1982): Higher-order functional variation displacement discontinuity elements. Int. J Rock Mech. Min. Sci. 19, 143-148. 
Crouch S. L., Starfield A. M. (1983): Boundary elements in solid mechanics. Allen \& Unwin, London, 322pp.

Dzik E. J., Lajtai E. Z. (1996): Primary fracture propagation from circular cavities loaded in compression. Int. J. Fract. 79, 49-64.

Ewy R. T., Cook N. G. W. (1990a): Deformation and fracture around cylindrical openings in rock-I. Observations and analysis of deformations. Int. J Rock Mech. Min. Sci. 27, 387-407.

Ewy R. T., Cook N. G. W. (1990b): Deformation and fracture around cylindrical openings in rock-II. Initiation, growth and interaction of fractures. Int. J Rock Mech. Min. Sci. 27, 409-427.

Finney J. L. (1979): A procedure for the construction of Voronoi polyhedra. J. Comput. Phys. 32, 137-143.

Fjær E., Holt R. M., Horsrud P., Raaen A. M., Risnes R. (1992): Petroleum related rock mechanics. Elsevier, Amsterdam, 338pp.

Hallbauer D. K., Wagner H., Cook N. G. W. (1973): Some observations concerning the microscopic and mechanical behaviour of quartzite specimens in stiff, triaxial compression tests. Int. J Rock Mech. Min. Sci. 10, 713-726.

Ingraffea A. R. (1987): Theory of crack initiation and propagation in rock. In: Atkinson B. K. (ed.), Fracture mechanics of rock. Academic Press, London, 71-110.

Kranz R. L. (1983): Microcracks in rocks: a review. Tectonophysics 100, 449-480.

Kuijpers J. S. (1999): Fracturing of brittle rock under compression: cause and effects in large quartzite discs. In: Proc., $9^{\text {th }}$ International Congress on Rock Mechanics, ISRM, Balkema, Paris, 627-633.

Kuijpers J. S., Napier J. A. L. (1996): Effective growth rules for macro fracture simulation in brittle rock under compression. In: Barla G. (ed.), Proc., International Symposium Eurock '96, 469-479.

Liu D., Wang S., Li L. (2000): Investigation of fracture behaviour during rock mass failure. Int. J Rock Mech. Min. Sci. 37, 489-497.

Malan D. F., Basson F. R. P. (1998): Ultra-deep mining: the increased potential for squeezing conditions. J. S. Afr. Inst. Min. Metallurg. 98, 353-363.

Malan D. F., Napier J. A. L. (1995): Computer modelling of granular material microfracturing. Tectonophysics 248, 21-37.

Martin C. D. (1997): The effect of cohesion loss and stress path on brittle rock strength. Can. Geotech. J. 34, 698-725.

Martin C. D., Kaiser P. K., McCreath D. R. (1999): Hoek-Brown parameters for predicting the depth of brittle failure around tunnels. Can. Geotechn. J. 36 (1), 136-151.

Martin C. D., Read R. S., Martino J. B. (1997): Observations of brittle failure around a circular test tunnel. Int. J Rock Mech. Min. Sci. 34, 1065-1073.

Napier J. A. L. (1990): Modelling of fracturing near deep level gold mine excavations using a displacement discontinuity approach. In: Rossmanith H.-P. (ed.), Proc., International Conference of the Mechanics of Jointed and Faulted Rocks, 709-715.

Napier J. A. L., Hildyard M. W. (1992): Simulation of fracture growth around openings in highly stressed brittle rock. J. S. Afr. Inst. Min. Metallurg. 92, 159-168.

Napier J. A. L., Malan D. F. (1997): A viscoplastic discontinuum model of time-dependent fracture and seismicity effects in brittle rock. Int. J Rock Mech. Min. Sci. 34, 10751089. 
Napier J. A. L., Peirce A. P. (1995): Simulation of extensive fracture formation and interaction in brittle materials. In: Rossmanith, H.-P. (ed.), Proc., Second International Conference on Mechanics of Jointed and Faulted Rock, 63-74.

Napier J. A. L., Daehnke A., Dede T., Hildyard M. W., Kuijpers J. S., Malan D. F., Sellers E. J., Turner P. A. (1997): Quantification of stope fracture zone behaviour in deep level gold mines. J. S. Afr. Inst. Min. Metallurg. 97, 119-134.

Olsson W. A., Peng S. S. (1976): Microcrack nucleation in marble. Int. J Rock Mech. Min. Sci. 13, 53-59.

Sellers E., Napier J. (1997): A comparative investigation of micro-flaw models for the simulation of brittle fracture in rock. Comput. Mech. 20, 164-169.

Shao J. F., Hoxha D., Bart M., Homand F., Duveau G., Souley M., Hoteit N. (1999): Modelling of induced anisotropic damage in granites. Int. J Rock Mech. Min. Sci. 36, 1001-1012.

Van de Steen B. (2001). Effect of heterogeneities and defects on the fracture pattern in brittle rock. PhD thesis KULeuven, 250pp.

Van de Steen B., Vervoort A., Napier J. A. L. (2001): Numerical modelling of fracture initiation and propagation in biaxial tests on rock samples. Int. J. Fract. 108, 165-191.

Zhao Y., Huang J., Wang R. (1993): Real-time SEM observations of the microfracturing process in rock during a compression test. Int. J Rock Mech. Min. Sci. 30, 643-652.

Zobak M. D., Moos D., Mastin L., Anderson R. N. (1985): Well bore breakouts and in situ stress. J. Geophys. Res. 90, 5523-5530.

Authors' address: André Vervoort, Katholieke Universiteit Leuven, Faculty of Engineering, Department of Civil Engineering, Kasteelpark Arenberg 40, B-3001 Leuven, Belgium; e-mail: andre.vervoort@bwk.kuleuven.ac.be 